\title{
Evaluation of Visual Examination of Stool as A Screening Test for Infant with Prolonged Neonatal Cholestasis Namely Biliary Atresia
}

\author{
MM SARKER ${ }^{\mathrm{a}}, \mathrm{ASMB} \mathrm{KARIM}^{\mathrm{b}}, \mathrm{S} \mathrm{HALDER}^{\mathrm{c}}$
}

\begin{abstract}
Introduction:

Neonatal cholestasis is a hepatobiliay disease characterized by biliary obstruction in the neonatal period. Biochemically it is evidenced by prolonged elevation of serum conjugated bilirubin beyond the first 14 days of life. ${ }^{1}$ Most common causes are biliary atresia and idiopathic neonatal hepatitis. ${ }^{3,4}$
\end{abstract}

Objective: To evaluate stool color as a screening test by visual inspection in infants with prolonged neonatal cholestasis.

Methodology: This was a cross-sectional analytic study, conducted in Pediatric Gastroenterology and Nutrition Department,BSMMU, Dhaka, from 3 September 2012 to 3 February 2013 about 6 month duration. Statistically calculated 38 infants with prolonged neonatal direct hyperbilirubinaemia beyond their 14 days of age were included in this study.

Results: The mean age of the subjects was 62.3 days with a standard deviation (SD) \pm 13.7 days. Male to female ratio was 1.2:1. All (100\%) the subjects were icteric and hepatomegaly was found in $94.7 \%$ subjects. Dark urine (84.2\%), pale stool (78.5\%), bleeding manifestations (31.8\%) and infection (29\%) were also observed. Thirty

\section{Introduction:}

Neonatal cholestasis is a hepatobiliay disease characterized by biliary obstruction in the neonatal period. Biochemically it is evidenced by prolonged

a. Dr. Mst Mukta Sarker, Lt Col and Classified Spl Paediatrics $\mathrm{CMH}-$ Chattogram

b. Prof Dr. ASM Bazlul Karim, Dept of Paediatric Gastroenterology and Nutrition, Bangabandhu Sheikh Mujib Medical University (BSMMU)

c. Dr. Soma Halder, Assistant Professor, Dept of Paediatrics , Shahabuddin Medical College, Dhaka

Adddress of Correspondence: Dr. Mst Mukta Sarker, MBBS, FCPS ( Paed), Lt Col and Classified Spl of Paediatrics, CMH-Chattogram, E-mail: muktasarker@hotmail.com, Mob: $+8801716319313$
(78.5\%) subjects had pale colored stool. Mean ( \pm SD) albumin and conjugated bilirubin levels were 3.68 $( \pm 1.88) \mathrm{gm} / \mathrm{dl}$ and $5.29( \pm 1.31) \mathrm{mg} / \mathrm{dl}$ respectively. $A L T$ and GGT level of the study subjects were $346.19 \pm 124.28 \mathrm{u} / \mathrm{dl}$ and $315 \pm 198.91 \mathrm{u} / \mathrm{l}$ respectively. Common ultrasonographic findings of the patients were non visualization of gallbladder $60.5 \%$, non-visualization of common bileduct 50\%, hepatomegaly 92.1\%, and triangular cord sign in portahepatis 7.9\%. Scintigraphy revealed impaired excretion into intestine $88.9 \%$ in majority of the subjects. Liver biopsy revealed liver architecture was preseved $65.8 \%$ bile duct proliferation $52.6 \%$, regenarating nodule was absent $65.8 \%$ gaint cell was present $52.6 \%$ portal tract inflammation was found in 47.4\%. Sensitivity of stool color in the diagnosis of neonatal cholestasis was found $90.6 \%$, specificity $83.3 \%$, accuracy $89.5 \%$, positive predictive value $96.7 \%$ and negative predictive value $62.5 \%$.

Conclusion: It can be concluded that stool color might be reliable indicator for screening of prolonged neonatal cholestasis namely biliary atresia.

Key wards: Biliary Atresia, Neonatal Cholestasis

(J Bangladesh Coll Phys Surg 2021; 39: 46-52)

DOI: https://doi.org/10.3329/jbcps.v39i1.50451

elevation of the serum levels of conjugated bilirubin beyond the first 14 days of life. ${ }^{1}$ Indicators of cholestasis are direct reacting bilirubin more than 34 $\mu \mathrm{mol} /$ liter or $2 \mathrm{mg} / \mathrm{dl}$ or direct acting bilirubin more than $20 \%$ of total serum bilirubin concentration. ${ }^{1,2}$ Most common causes of direct acting bilirubin are biliary atresia and idiopathic neonatal hepatitis accounting for $50-70 \%$ cases. ${ }^{3,4}$ Cholestasis is defined as impairment in the excretion of bile, which can be caused by defects in intrahepatictransmembrane transport of bile, or mechanical obstruction to bile flow. The biochemical features of cholestasis reflect the retention of components of bile in the serum. ${ }^{11}$ Neonatal cholestasis occur in $0.04 \%$ to $2 \%$ live birth. ${ }^{3}$ Biliary atresia occurs approximately 1/18000 live birth in Western Europe. ${ }^{5}$ In the world the reported incidence varies from 
5/100000 to $32 / 100000$ live birth and is highest in Asia and Pacific region. Females are affected slightly more than the males.

Cholestasis in a new born can be due to infectious, genetic, metabolic or undefined abnormalities giving rise to functional impairment of hepatic excretory function of bile secretion or mechanical obstruction of bile flow. As a result affected infants have icterus, dark urine and acholic (pale) stool. ${ }^{4}$ Sometimes, due to partial obstruction of bile flow, stool is clay colored, pale yellow or light yellowish colored. ${ }^{4,5}$ If there is no atresia, stool color may be yellowish, brown and greenish. ${ }^{5}$ Presence of stool pigment (cholic) exclude extra hepatic biliary atresia, while its absence is suggestive of extra hepatic biliary atresia. $^{6-8}$

The diagnosis of biliary atresia may be difficult because of confusion with physiological jaundice (due to immaturity of the infant liver) and breast milk jaundice. ${ }^{9}$ Physiological jaundice normally lasts 2-3 days in normal term babies, while breast milk jaundice can last for up to 4 weeks. These physiological conditions can be differentiated from liver disease because in both physiological jaundice and breast milk jaundice, the bilirubin in the blood is mainly unconjugated (indirect), where as in neonatal cholestasis bilirubin is conjugated (direct), typically $34 \mu \mathrm{mol} / 1$ or $20 \%$ of total. ${ }^{10}$ Neonatal cholestasis is not treated timely it may causes portal hypertension, ascites, coagulopathy, cirrhosis of liver and subsequent death within first year of life. ${ }^{9,11}$

The most important concern cholestatic disease should be the early and rapid differentiation between medical versus surgical causes. Sequences of paraclinical investigations such as biochemical tests, ultrasonography, hepatobiliary scintigraphy, liver biopsy and ultimately intraoperative cholangiographies as a gold standard are employed to differentiate between surgical and medical conditions as soon as possible. Biliary atresia must be distinguished immediately, as early surgical intervention is required. Bile flow rate after the 'Kasai' procedure is higher if the procedure is performed before the infant reaches two months of age. , $^{8,1}$

When there is cholestasis stool will become clay colored due to lack of bile pigment. So, stool color indirectly could be a screening test for detection of neonatal cholestasis. Brown et $\mathrm{al}^{10}$ conducted a study for visual stool examination among 23 infants and found that this visual examination of stool was a helpful investigation particularly for clinician in a peripheral hospital where there was less access to specialized investigations. Rouzrokh et al ${ }^{7}$ observed that detection of neonatal cholestasis by examining the color of the stool had a sensitivity and specificity of $100 \%$ and $83 \%$ respectively. The positive predictive value and negative predictive value were $81 \%$ and $100 \%$ respectively. A mass screening program for detection of biliary atresia using a stool color card was conducted and it was proved that it was a sensitive and specific screening test in detecting biliary atresia. ${ }^{8}$ Tseng et al. reported that the corrective operation for biliary atresia within 60 days were $68.9 \%$ before and $73.6 \%$ after stool color screening test program. ${ }^{6}$ The aim of this study was to evaluate stool color as a screening test by visual inspection in infants with prolonged neonatal cholestasis namely biliary atresia and to determine the sensitivity, specificity, positive predictive value, negative predictive value and accuracy of visual stool color examination as screening test for diagnosis of biliary atresia considering liver biopsy as the gold standard test.

\section{Methods:}

This cross-sectional analytic study was conducted in Pediatric Gastroenterology and Nutrition Department, BSMMU Shahbagh, Dhaka, from 3 September 2012 to 3 February 2013. Prior to the commencement of this study the objectives of this study along with risks and benefit were fully explained to the parents of subjects and then informed written consent was taken from each parent. It was assured that all information and records would be kept confidential and the procedure would be helpful for both the physician and the patient in making rational approach of the case management. Ethical clearance from the department was taken.

First statistically calculated 38 infants with prolonged neonatal direct hyperbilirubinaemia beyond their 14 days of age admitted in Paediatric Gastroenterology and Nutrition ward in BSMMU were selected. Soon after selection stool was collected in a container and stool color was observed by the researcher herself by usining standard infant stool color card and then by two competent consultants of the department to eliminate observation bias. After those relevant laboratory examinations (serum bilirubin, ALT, PT, and GGT) with ultrasonography, liver scintigraphy were carried out. Finally suspected cases of biliary atresia were confirmed by histopathology from liver biopsy. 
Collected data was checked every day carefully to identify the errors in collecting data. Data processing was consisted of inclusion of patients, development of research instrument, editing of collected data, entering data into computer using computer soft-ware SPSS- 17, preparation of dummy tables, analysis and interpreting of data.

\section{Results:}

The mean age of the subjects was 62.3 days with a standard deviation (SD) \pm 13.7 days and their age ranged from 42 to 84 days. (Table:I) Male to female ratio was 1.2 :1. (Fig:1) All (100\%) the subjects were icteric and hepatomegaly was found in $94.7 \%$ subjects. Dark urine $(84.2 \%)$, pale stool $(78.5 \%)$, bleeding manifestations (31.8\%) and infection (29\%) were also observed. (Table:II) Thirty (78.5\%) subjects had pale colored stool. (Fig:2) Mean ( \pm SD) albumin and conjugated bilirubin levels were 3.68
$( \pm \mathbf{1 . 8 8}) \mathrm{mg} / \mathrm{dl}$ and $5.29( \pm \mathbf{1 . 3 1}) \mathrm{mg} / \mathrm{dl}$ respectively. ALT and GGT level of the study subjects were $346.19 \pm 124.28 \mathrm{u} / \mathrm{dl}$ and $315 \pm 198.91 \mathrm{u} / 1$ respectively. (Table: III) Common ultrasonographic findings of the patients were non visualization of gallbladder $(60.5 \%)$, non visualization of common bileduct $(50 \%)$, hepatomegaly $(92.1 \%)$, and triangular cord sign in portahepatis $(7.9 \%)$. (Table: IV) Scintigraphy revealed impaired excretion into intestine $(88.9 \%)$ in majority of the subjects. (table: V) Liver biopsy revealed liver architecture was preseved $65.8 \%$ bile duct proliferation $52.6 \%$, regenarating nodule was absent $65.8 \%$ gaint cell was present $52.6 \%$ portal tract inflammation was found in $47.4 \%$. (Table: VI). Sensitivity of stool color in the diagnosis of neonatal cholestasis was found $90.6 \%$, specificity $83.3 \%$, accuracy $89.5 \%$, positive predictive value $96.7 \%$ and negative predictive value $62.5 \%$. (Table: VIII)

Table I: Distribution of studied subjects by age group $(n=38)$

\begin{tabular}{lcc}
\hline Age group (Days) & Number & Percentage \\
\hline $42-55$ & 20 & 52.6 \\
$56-69$ & 05 & 13.2 \\
$\geq 70$ & 13 & 34.2 \\
\hline Mean \pm SD & \multicolumn{2}{c}{$62.25 \pm 13.68$} \\
\hline Range (Min-max) & $42-84$ \\
\hline
\end{tabular}

Distribution of the studied subjects by gender $(n=38)$

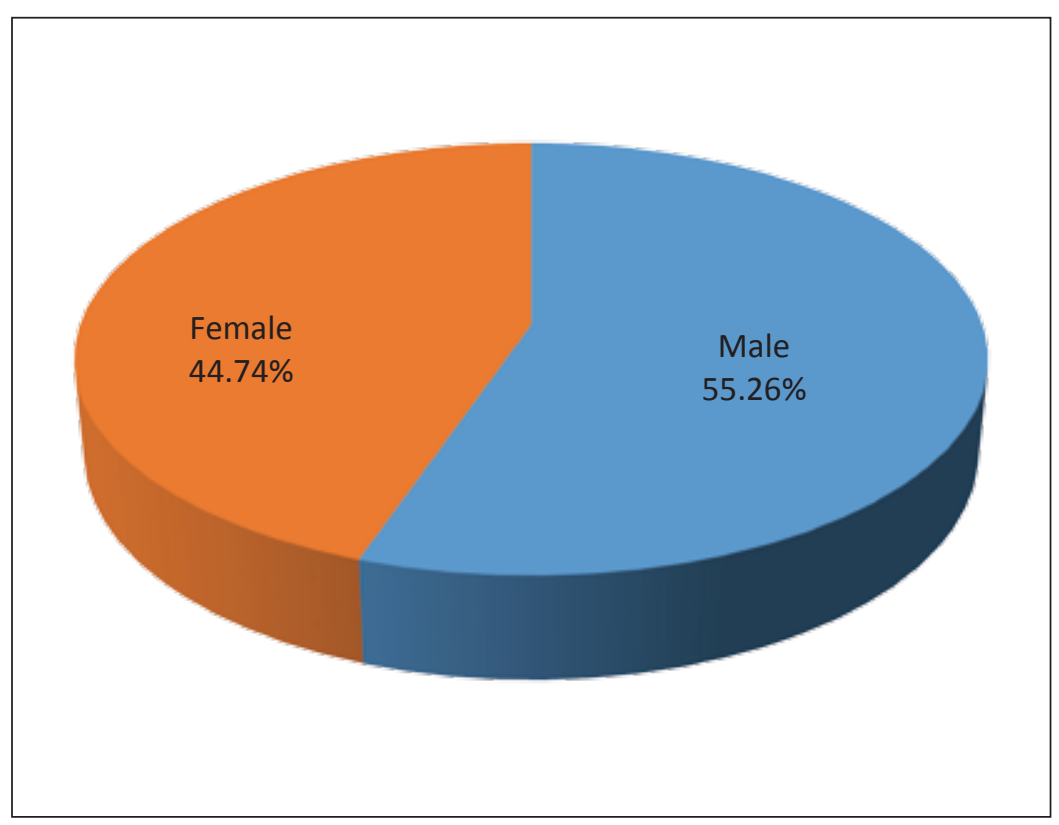

Figure 1: Pie chart showing gender distribution of the studied subjects. 
Table II: Distribution of studied subject by Clinical presentations

\begin{tabular}{lcc}
\hline Clinical features & Number & Percentage \\
\hline Jaundice & 38 & 100 \\
Hepatomegaly & 36 & 94.8 \\
Dark urine & 32 & 84.2 \\
Pale stool & 30 & 78.5 \\
Bleeding manifestation & 12 & 31.6 \\
Hepato-splenomegaly & 06 & 15.8 \\
Associated infection & 11 & 29.00 \\
\hline
\end{tabular}

Distribution of studied subjects by stool colour $(n=38)$

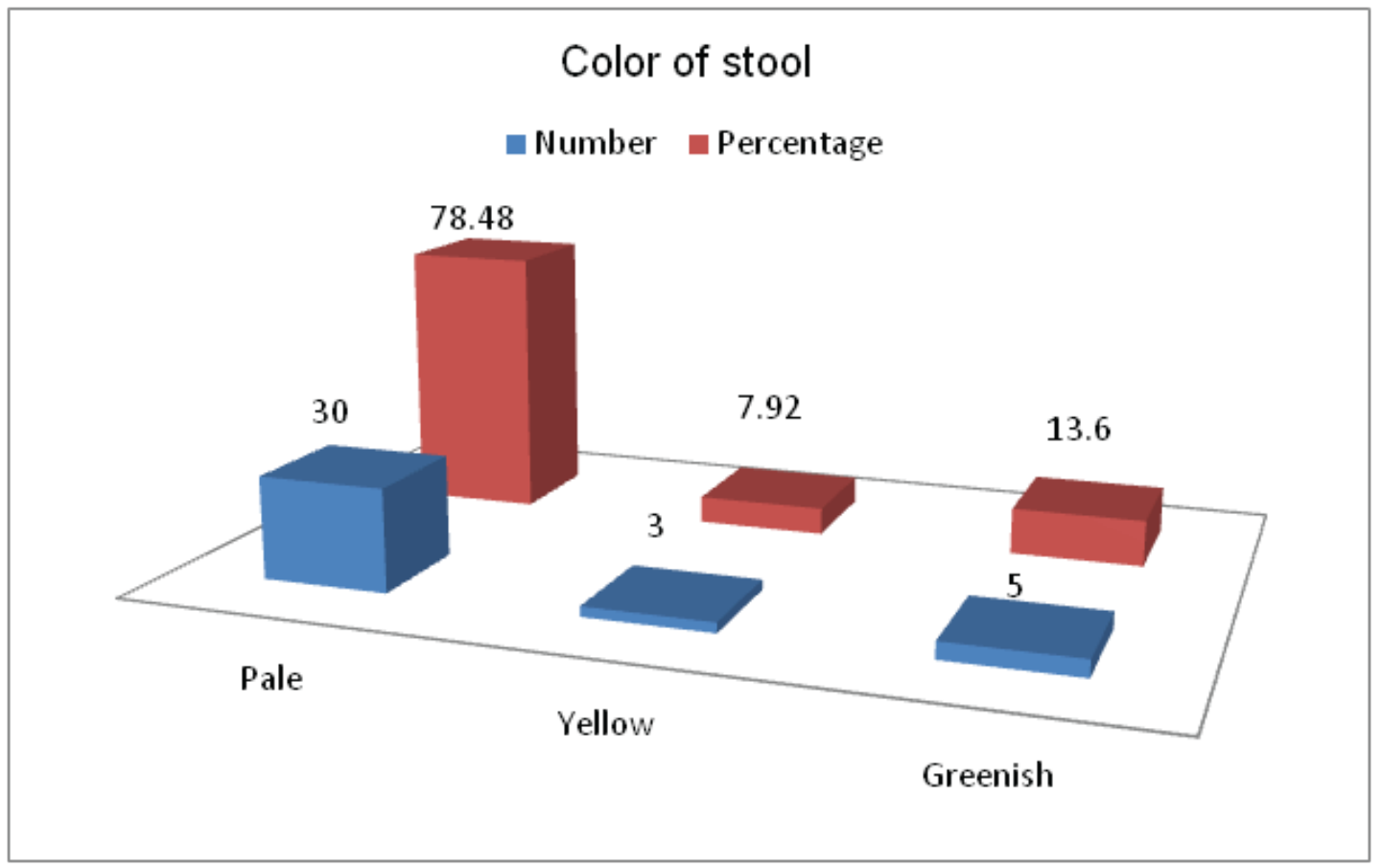

Figure 2: Bar diagram showing color of stool in the studied subjects $(n=38$

Table III: Laboratory findings of the study subjects

\begin{tabular}{lcc}
\hline Traits & Mean \pm SD & Maximum- Minimum \\
\hline Haemogloin $(\mathrm{gm} / \mathrm{dl})$ & $8.58 \pm 2.46$ & $10.5-7.5$ \\
Serum albumin $(\mathrm{gm} / \mathrm{dl})$ & $3.68 \pm 1.88$ & $5.1-3.2$ \\
Serum bilirubin $(\mathrm{mg} / \mathrm{dl})$ (conjugated) & $5.29 \pm 1.31$ & $7.8-4.3$ \\
ALT $(\mathrm{u} / \mathrm{dl})$ & $346.19 \pm 124.28$ & $610-60.59$ \\
GGT $(\mathrm{U} / \mathrm{L})$ & $315 \pm 198.91$ & $551-86$ \\
Prothrombin time (seconds) & $17 \pm 5$ & $23-12$ \\
FT4(ngm/dl) & $1.56 \pm 0.84$ & $2.5-0.92$ \\
TSH (mIU/L) & $5.68 \pm 3.49$ & $9.1-1.9$ \\
\hline
\end{tabular}


TableIV: Distribution of studied subjects by ultrasonographic findings

\begin{tabular}{lcc}
\hline Ultrasonographic findings & Number & Percentage \\
\hline Hepatomegaly & 35 & 92.1 \\
Non visualization of gall bladder & 23 & 60.5 \\
Non visualization of common bile duct & 19 & 50.0 \\
Normal gall bladder & 08 & 21.1 \\
Triangular cord sign in portahepatis & 03 & 07.9 \\
\hline
\end{tabular}

Table V: Distribution of the studied subjects by scintigraphic findings

\begin{tabular}{lcc}
\hline Scintigraphic findings & Number & Percentage \\
\hline Normal uptake by liver & 36 & 94.7 \\
Normal excretion into intestine & 04 & 11.0 \\
Impaired excretion into intestine & 32 & 88.9 \\
Poor uptake by liver & 02 & 5.3 \\
\hline
\end{tabular}

Table VI: Distribution o the studied subjects by liver biopsy findings

\begin{tabular}{lcc}
\hline Liver biopsy findings & Number & Percentage \\
\hline Architecture liver & 13 & 34.2 \\
Disturbed & 25 & 65.8 \\
Preserver & 13 & \\
Bile duct & 20 & 34.2 \\
Normal & 05 & 52.6 \\
polyfereted & & 13.15 \\
paucity & 25 & 65.8 \\
Regenerating nodule & 13 & 34.2 \\
No & & \\
Yes & 20 & 52.6 \\
Gaint cell & 18 & 47.3 \\
No & & \\
Yes & 09 & 23.7 \\
Portal trait & 18 & 47.4 \\
Normal & 11 & 28.9 \\
Inflammation & & \\
Fibrosis & & \\
\hline
\end{tabular}

Table VII: Sensitivity of stool color at visual examination in the diagnosis of neonatal cholestasis

\begin{tabular}{lccc}
\hline Pale stool color & Biliary atresia present & Biliary atresia absent & Total \\
\hline Present & $29(\mathrm{TP})$ & $1(\mathrm{FP})$ & 30 \\
Absent & $3(\mathrm{FN})$ & $5(\mathrm{TN})$ & 08 \\
\hline Total & 32 & 6 & 38 \\
\hline
\end{tabular}

Table VIII: Performance of stool color in the diagnosis of neonatal cholestasis

\begin{tabular}{lllll}
\hline Sensitivity & Specificity & Accuracy & PPV & NPV \\
\hline $90.6 \%$ & $83.3 \%$ & $89.5 \%$ & $96.7 \%$ & $62.5 \%$ \\
\hline
\end{tabular}




\section{Discussion:}

Cholestasis is defined as impairment in the excretion of bile, which can be caused by defects in intrahepatic-transmembrane transport of bile, or mechanical obstruction to bile flow. The biochemical features of cholestasis reflect the retention of components of bile in the serum. ${ }^{11}$ The pattern and severity of each of these abnormalities varies with the underlying disorders. Elevated conjugated bilirubin is the predominant characteristic features in most of the causes of neonatal cholestasis. ${ }^{11}$ In biliary atresia the body accumulates an excess of bilirubin, it turns yellow (jaundice), passes of conjugated bilirubin through urine cause dark urine, due to lack of bile pigment the stools are pale. ${ }^{13}$

With the aim to evaluate stool color as a screening test by visual inspection in infants with prolonged neonatal cholestasis this cross sectional analytic study was carried out in infants with prolonged neonatal cholestasis on 38 subjects aged 42-84 days in the Paediatric Gastroenterology and Nutrition Department of BSMMU, Dhaka.

In this current study it was seen that mean age of presentation was 48.25 days, majority of the subjects $52.6 \%$ were found in the age group of 42-56 days (Table:I). This study result was similar with that of common epidemiological background of neonatal cholestasis. ${ }^{1,2,10,12}$ There were $55.3 \%$ were male and $44.7 \%$ female baby and male to female ratio was 1.2 : 1(Fig:1). Previous report revealed that neonatal cholestasis had slightly more male predominance. ${ }^{5}$

Previous studies ${ }^{8,10,16,17}$ showed that the detection of cholestasis rests on the clinical recognition of jaundice, pale stool, and/or dark urine with a palpable liver in most of the cases. Our present study showed that all the subjects presented with jaundice. Hepatomegaly was found in $94.7 \%$ subjects, dark urine $84.2 \%$, pale stool $78.5 \%$, bleeding manifestations $31.6 \%$, infection $28.9 \%$ and hepato-splenomegaly was observed in $15.8 \%$ subjects (Table:II). Thirty (78.5\%) subjects had pale colored stool, three $(7.9 \%)$ had yellow colored and five (13.6\%) had greenish colored stool Fig:2). American Academy of Pediatrics ${ }^{2,5,11}$ reported that cholestasis in neonatal period should be investigated for conjugated bilirubin and GGT along with other relevant laboratory investigations and it was seen that conjugated hyperbilirubinemia with a raised GGT level was seen in most of the cases of neonatal cholestasis. Similar comparable results were seen in the present study where mean $( \pm$ SD) conjugated bilirubin level was $5.29( \pm \mathbf{1 . 3 1}) \mathbf{m g} / \mathbf{d l}$ and GGT level of the study subjects was $315 \pm 198.91 \mathrm{u} / \mathrm{l}$ (Table:III).

There are other several imaging investigations like ultrasonography and scintigraphy of hepatobiliary system. Kanegawa et al $(2003)^{21}$ described that in neonatal cholestasis, "triangular cord" sign was one of the important signs of cholestasis. Others ${ }^{22,23}$ found that there were nonvisualization of gall bladder or bile duct occurred in subjects with neonatal cholestasis. Similar comparable result was showed in the present study where it was seen that the common sonographic findings of the studied subjects were non visualization of gall bladder $60.5 \%$, non visualization of common bile duct $50 \%$, hepatomegaly $92 \%$, and Triangular cord sign at portahepatis 7.9\% (TableIV). Scintigraphy revealed impaired excretion into intestine $88.9 \%$ in majority of the subjects in this current study (Table:VII). Nonvisualization of radioactivity within the intestine was considered to be an abnormal result, indicating biliary obstruction in previous studies. $^{22,23} 52.6 \%$ our cases showed ductular proliferation, $47.4 \%$ portal trait inflammation and $28.9 \%$ fibrosis (Table:VI) this finding supports with Archana Rastogi et al. ${ }^{26}$ In this current series it was observed that out of 38 subjects 30 had pale-colored stool and 8 subjects had normal colored stool. Among the pale-colored stool (30) 29 subjects were diagnosed as biliary atresia and 1 other than biliary atresia. Among the normal colored stool (8) 3 were diagnosed as biliary atresia. Brown et al also found similar findings in his study. ${ }^{10}$ Presence of bile pigment in biliary atresia may be explained by In early stages of biliary atresia child may pass intermittent pale colored and normal colored stool. If bilirubin level high it may oozes from gut wall and can pigment the stool. In female child pale stool sometimes mixed with dark urine and may give false impression of pigmented stool. ${ }^{11}$ Pale colored stool in other than biliary atresia can explained by in hepatitis ( infection, metabolic) severe hepatic inflammation may cause temporary biliary obstruction and lead transient acolic (pale) stool. ${ }^{9}$ Sensitivity of stool color in the diagnosis of biliary atresia was found to be $90.6 \%$, specificity $83.3 \%$, accuracy $89.5 \%$, positive predictive value $96.7 \%$ and negative predictive value $62.5 \%$. Rouzrokh et $\mathrm{al}^{7}$ observed that detection of neonatal cholestasis by examining the color of the stool had a sensitivity and specificity of $100 \%$ and $83 \%$ respectively with positive predictive value and negative predictive value of $81 \%$ and $100 \%$ respectively. 


\section{Conclusion:}

From the findings of the present work it can be concluded that stool color is a reliable indicator for screening neonatal cholestasis namely biliary atresia.

\section{References:}

1. Chardot C, Biliary atresia. Orphanet Encyclopedia. 2005; 5:11-14.

2. Kader HH, Balistreri WF. Cholestasis. In: Kliegman RM, Santon BF, St.Geme JW, Schor NF.(Eds). Nelson Textbook of Pediatrics.19th ed. Philadelphia: WB Sounders Company; 2010.p1381-1388.

3. Benchimol EI, Walsh CM, Ling SC. Early diagnosis of neonatal cholestaticjaundice. Can Fam Physician. 2009;55:1184-92.

4. Karim ASMB, Kamal M. Cholestasis jaundice during infancy: experience at a tertiary-care center in Bangladesh. Indian J Gastroenterol. 2005;24:456-458.

5. Hsiao CH, Chang MW, Chen Wl. Universal Screening for Biliary Atresia Using an Infant Stool Color Card in Taiwan. Hepatology. 2008;12:1233-1240. https:// doi.org/10.1002/ hep.22182, PMid:18306391

6. Tseng JJ, Lai MS, Lin MC, Fu YC. Stool Color Card Screening for Biliary Atresia. Pediatrics. 2011;128 :1152-1160. https://doi.org/10.1542/ peds.2010-3495, PMid:22025588

7. Rouzrokh M, Sobhiyeh MR, Heibatollahi M. The Sensitvity, Specificity, Positive and Negative Predictive Values of Stool Color test, Triangular Cord Sign and Hepatobiliary Scintigraphy in Diagnosis of Infantile Biliary Atresia. IRCMJ. 2009; 11: 425-430.

8. Chang MH. Screening for Biliary Atresia. Med J. 2006; 29:231-233. https://doi.org/10.1016/ S87565005(08)70330-5

9. Bakshi B, Sutcliffe A, Akindolie M. How reliably can paediatric professionals identify pale stool from cholestatic newborns?.Arch Dis Child Fetal Neonatal Ed. 2012:97;387. https://doi.org/10.1136/ fetalneonatal2010-209700, PMid:22933100

10. Brown N, Househam KC. Visual stool examination- a screening test for infants with prolonged jaundice. S Aft Med J.1990; 77 : 358-359.

11. Deirdre AK, Davenport M. Current management of biliary atresia.Br Med J. 2012;12:1132-1135.

12. Dick MC, Mowat AP. Hepatitis syndrome in infancy-an epidemiological survey with 10 year follow up. Arch Dis Child. 1985; 60:512. https://doi.org/10.1136/ adc.60.6.512, PMid:3874604 PMCid:PMC1777358

13. Balistreri WF. Neonatal cholestasis. J Pediatr. 1985;106:171-175. https://doi.org/10.1016/ S00223476(85)80282-1
14. Moyer V, Freese D, Whitington P, Olson A, Fred M, Richard B, et al. Guideline for the Evaluation of Cholestatic Jaundice in Infants: Recommendations of the North American Society for Pediatric Gastroenterology, Hepatology and Nutrition. JPGN. 2004;39:115-128. https:// doi.org/10.1097/ 00005176200408000-00001, PMid:15269615

15. Westwood A. The analysis of bilirubin in serum. Ann ClinBiochem.1991; 28:119-30. https:// doi.org/ 10.1177/000456329102800202, PMid: 1859150

16. Faust TW, Reddy KR. Postoperative jaundice. Clin Liver Dis. 2004; 8:151-66. https://doi.org/10.1016/ S1089-3261(03)00130-2

17. Kirk JM. Neonatal jaundice: a critical review of the role and practice of bilirubin analysis. Ann ClinBiochem.2008;45:452-62. https://doi.org/10.1258/ acb.2008.008076, PMid:18753416

18. Roche SP, Kobos R. Jaundice in the adult patient. Am Fam Physician. 2004; 69: 299-304.

19. Davis AR, Rosenthal P, Escobar GJ, Newman TB. Interpreting conjugated bilirubin levels in newborns. J Pediatr. 2011; 2:158:562. https://doi.org/10.1016/ j.jpeds.2010.09.061, PMid:21074172 PMCid:PMC3058149

20. McLin VA, Balistereri WF. Approach to neonatal cholestasis. In: Pediatric Gastrointestinal Disease: Pathopsychology, Diagnosis, Management, 4th, Walker WA, Goulet O, Kleinman RE, et al (Eds), BC Decker, Ontario 2004: 1079.

21. Kanegawa K, Akasaka Y, Kitamura E. Sonographic diagnosis of biliary atresia in pediatric patients using the "triangular cord" sign versus gallbladder length and contraction. AJR Am J Roentgenol. 2003;181: 1387. https://doi.org/10.2214/ajr.181.5.1811387, PMid: 14573442

22. Lee CH, Wang PW, Lee TT. The significance of functioning gallbladder visualization on hepatobiliaryscintigraphy in infants with persistent jaundice. J Nucl Med. 2000;41: 1209.

23. Majd M, Reba RC, Altman RP. Hepatobiliaryscintigraphy with $99 \mathrm{mTc}$-PIPIDA in the evaluation of neonatal jaundice. Pediatrics. 1981 67:140.

24. Iinuma $Y$, Narisawa $R$, Iwafuchi $M$. The role of endoscopic retrograde cholangiopancreatography in infants with cholestasis. J PediatrSurg. 2000;35: 545-548. https://doi.org/10.1053/jpsu.2000.0350545, PMid:10770378

25. Norton KI, Glass RB, Kogan D. MR cholangiography in the evaluation of neonatal cholestasis: initial results. Radiology.2002;222:687. https://doi.org/ 10.1148/ radiol.2223010969, PMid:11867786

26. Rastogi A, Krishnani N, Kumar S. Histopathological features and accuracy for diagnosing biliary atresia by prelaparotomy liver biopsy in developing countries. J Gastroenterol Hepatol. 2009;97:102 